\title{
(6) OPEN ACCESS \\ Efficacy of a movement control injury prevention programme in adult men's community rugby union: a cluster randomised controlled trial
}

\author{
Matthew J Attwood, ${ }^{1,2}$ Simon P Roberts, ${ }^{1}$ Grant Trewartha, ${ }^{1}$ Mike E England, ${ }^{3}$ \\ Keith A Stokes ${ }^{1}$
}

- Additional material is published online only. To view please visit the journal online (http://dx.doi.org/10.1136/ bjsports-2017-098005)

${ }^{1}$ Department for Health, University of Bath, Bath, UK ${ }^{2}$ School of Sport and Health Sciences, Cardiff Metropolitan University, Cardiff, UK ${ }^{3}$ Rugby Football Union, Twickenham, London, UK

Correspondence to Dr Keith A Stokes, Department for Health, University of Bath, Claverton Down, Bath BA2 7AY, UK; k.stokes@bath.ac.uk

Accepted 12 September 2017 Published Online First 21 October 2017
Check for updates

To cite: Attwood MJ, Roberts SP, Trewartha G, et al. Br J Sports Med 2018;52:368-374

\section{ABSTRACT \\ Background Exercise programmes aimed at reducing injury have been shown to be efficacious for some non-collision sports, but evidence in adult men's collision sports such as rugby union is lacking. \\ Objective To evaluate the efficacy of a movement control injury prevention exercise programme for reducing match injuries in adult men's community rugby union players.}

Methods 856 clubs were invited to participate in this prospective cluster randomised (single-blind) controlled trial where clubs were the unit of randomisation. 81 volunteered and were randomly assigned (intervention/ control). A 42-week exercise programme was followed throughout the season. The control programme reflected 'normal practice' exercises, whereas the intervention focused on proprioception, balance, cutting, landing and resistance exercises. Outcome measures were match injury incidence and burden for: (1) all $\geq 8$ days time-loss injuries and (2) targeted (lower limb, shoulder, head and neck, excluding fractures and lacerations) $\geq 8$ days timeloss injuries.

Results Poisson regression identified no clear effects on overall injury outcomes. A likely beneficial difference in targeted injury incidence (rate ratio (RR), $90 \% \mathrm{Cl}=0.6,0.4$ to 1.0$)$ was identified, with a $40 \%$ reduction in lowerlimb incidence (RR, $90 \% \mathrm{Cl}=0.6,0.4$ to 1.0$)$ and a $60 \%$ reduction in concussion incidence $(\mathrm{RR}, 90 \% \mathrm{Cl}=0.4,0.2$ to $0.7)$ in the intervention group. Comparison between arms for clubs with highest compliance ( $\geq$ median compliance) demonstrated very likely beneficial $60 \%$ reductions in targeted injury incidence $(\mathrm{RR}, 90 \% \mathrm{Cl}=0.4,0.2$ to 0.8$)$ and targeted injury burden ( $\mathrm{RR}, 90 \% \mathrm{Cl}=0.4,0.2$ to 0.7$)$.

Conclusions The movement control injury prevention programme resulted in likely beneficial reductions in lower-limb injuries and concussion. Higher intervention compliance was associated with reduced targeted injury incidence and burden.

\section{INTRODUCTION}

Sports injuries negatively influence team success ${ }^{12}$ and may lead to withdrawal from sports participation. ${ }^{3}$ Injuries are also associated with secondary degenerative disease including osteoarthritis, ${ }^{56}$ which can impact on long-term quality of life. ${ }^{7}$ There has not been a large-scale movement control-informed injury prevention randomised controlled trial in adult men's community rugby union, despite a need to minimise injury rates to maximise sports participation and maintain players' long-term health.
Exercise-based injury prevention interventions including FIFA $11+{ }^{8}$ focus on reducing lower-limb injuries by means of exercises targeting balance, coordination, strength and power. In soccer, FIFA $11+$ has been reported to reduce injury incidence rates by between $32 \%$ and $72 \% .{ }^{10}$ However, in addition to the injury mechanisms common in soccer, rugby union (rugby) has additional contact/collision events. In community rugby, $80 \%$ of match injuries are associated with contact events ${ }^{11}$ compared with $44 \%$ in community soccer. ${ }^{12}$ The high-impact collision nature of the rugby tackle ${ }^{13}$ can result in blunt force trauma injuries. For example, fractures and lacerations account for $27 \%$ of all head injuries. ${ }^{14}$ Similarly, acromioclavicular joint dislocation is the most common rugby shoulder injury, ${ }^{15}$ where the injury mechanism is commonly a direct impact of the player's shoulder with the ground during a tackle. ${ }^{16}$ Such injuries are likely to be difficult to prevent through movement control programmes.

Knee and ankle ligament injuries combined with hamstring injuries account for 33\% of injuries overall and are the most common non-contact rugby injury diagnoses. ${ }^{11}$ Importantly, injury prevention programmes have reduced knee ( $70 \%$ reduction) and ankle sprains (62\% reduction) ${ }^{17}$ as well as hamstring strains (70\% reduction). ${ }^{18}$ Although FIFA $11+$ was designed to reduce lower-limb injuries in soccer, implementing the programme in basketball reduced lower-limb injury by $32 \% .{ }^{19}$ This indicates that the type of exercises included in FIFA 11+ may be appropriate across sports where lower-limb injuries predominate. Lower-limb injuries are common in rugby, but upper-limb and head and neck injuries account for $41 \%$ of all injuries ${ }^{11}$ compared with $6 \%$ in soccer. ${ }^{20}$ The profile of injuries in community rugby therefore warrants a new movement control exercise programme.

The aim of this study was to investigate the efficacy of a rugby-specific movement control programme to reduce injury risk in adult men's community rugby union players.

\section{METHODS}

\section{Trial design and randomisation}

This prospective cluster randomised control trial was designed in accordance with the CONSORT framework for cluster randomised trials. ${ }^{21}$ The playing population from which the study sample was recruited has been described previously as semi-professional (Rugby Football Union (RFU) levels 3-4; highest level of English community 


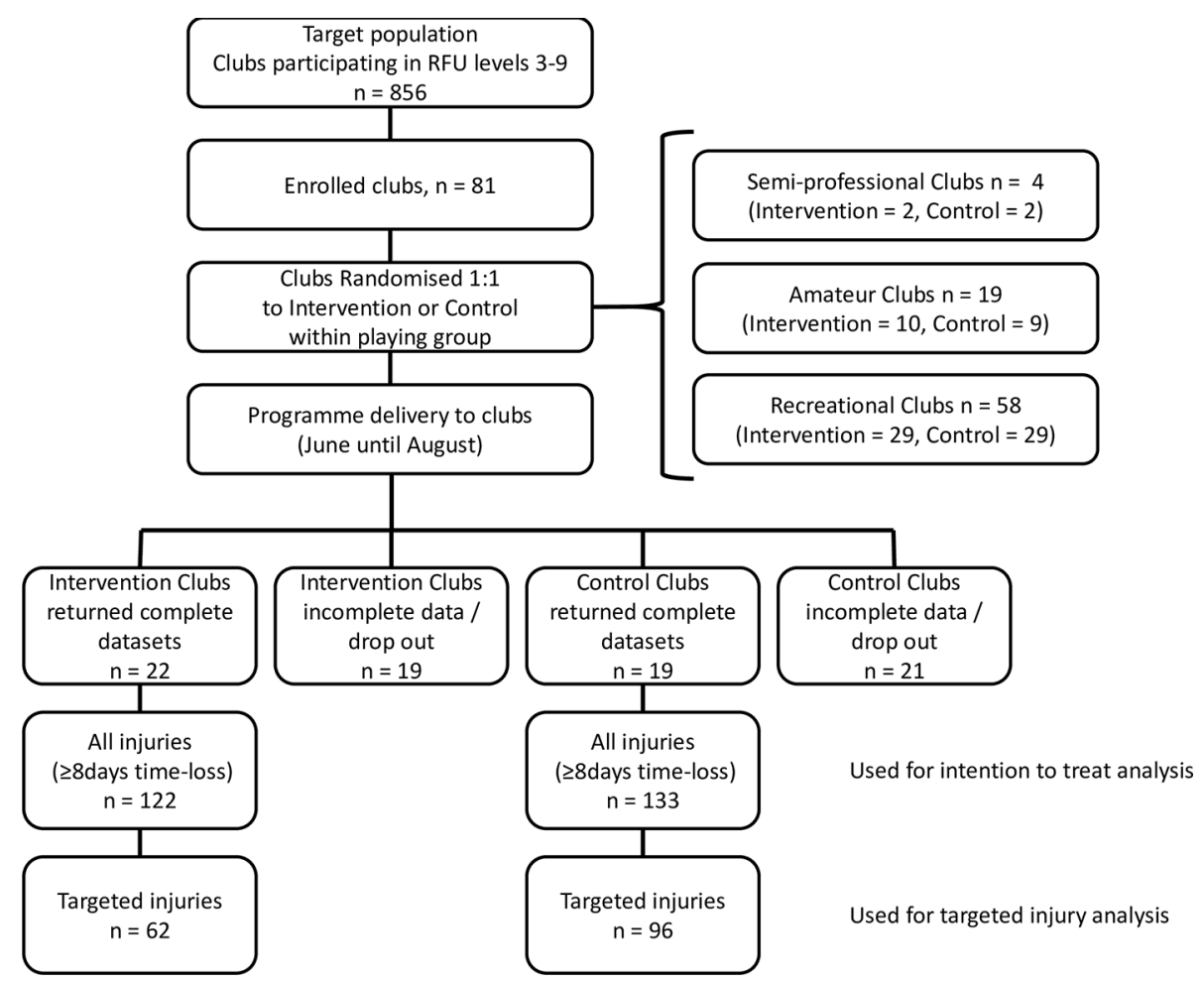

Figure 1 Flow chart of clubs through study period. RFU, Rugby Football Union.

rugby), amateur (RFU levels 5-6) and recreational (RFU levels 7-9). ${ }^{11}$ Injury incidence varies across these playing categories, ${ }^{11}$ and therefore, recruited clubs were stratified by playing level before being randomly allocated to the intervention or control group.

\section{Ethical approval}

The study was approved by the Research Ethics Approval Committee for Health, University of Bath, UK (Reference: EP14/15142).

\section{Sample size}

The required sample size was estimated ${ }^{22}$ at club level, indicating 54 clubs (27 clubs per trial arm, intervention/control) for a minimally important $(\alpha=0.05)$ injury burden rate ratio (RR) of 0.70 or less based on expected injury burden of 899 days/1000 player match-hours ${ }^{23}$ in the control group and anticipated exposure of 480 player match-hours per club (cluster). This allowed for an anticipated $50 \%$ drop-out rate and was adjusted for cluster coefficient $(k=0.26){ }^{23}$

\section{Study setting and recruitment}

Between March and June 2015, before the 2015/2016 preseason, 856 adult men's community rugby clubs competing in RFU league levels 3-9 in England were invited to participate in this study (figure 1). Inclusion criteria were that clubs must have access to a registered healthcare practitioner for injury diagnoses (sports therapists, osteopaths, chiropractors, physiotherapists or physicians).

\section{Programme design}

Before the 2014/2015 preseason, a review of successful injury prevention exercises from different sports settings was conducted alongside a review of adult men's community rugby injury epidemiology. An evidence-informed injury prevention exercise programme reflecting the injury profile of community rugby players was developed following discussion with an expert 'Technical Group' of sports medicine researchers, physiotherapists and strength and conditioning specialists that specialised in human movement, injury prevention, epidemiology and rehabilitation and a rugby coach. The intervention programme included proprioceptive, mobility and strengthening exercises within a progressive structure targeting the lower limb, shoulder, head and neck. The control programme included dynamic stretching and non-targeted resistance exercises presented in a similar progressive format to the intervention. A pilot trial was conducted during the 2014-2015 season in 16 clubs. Delivery agents (typically coaches) from pilot study clubs were interviewed at the end of this season to determine factors that affected implementation, following which the exercise programmes were modified. Revised programmes were examined by a second expert 'Technical Group' including strength and conditioning coaches, sports physiotherapists and sports medicine researchers.

\section{Exercise programmes}

The final exercise programmes included seven 6-week progressive phases spanning the 2015/2016 rugby preseason and inseason period to be used at training sessions (twice weekly) and prematch (once weekly). Programmes recommended 5-10 min of small-sided games after which the main content lasted $15 \mathrm{~min}$. The control programme followed a raise, activate, mobilise and potentiate format ${ }^{24}$ incorporating whole-body dynamic stretching and resistance exercises, such as partner grappling, front planks, press-ups and sprint drills, before finishing with high-intensity running exercises. The intervention warm-up incorporated balance/proprioceptive exercises, resistance and perturbation exercises and sport-related landing, cutting and plyometric exercises. Proprioception and balance exercises progressed through alterations including the use of upper-limb movement, performing the exercises with eyes closed and thus 
removing the visual component to balance and by perturbations in frontal and sagittal planes. Dynamic stability exercises targeting upper and lower limbs progressed in load by altering the number of sets and reps, intensity and by variations in the directions of movement. Resistance exercises progressed in duration or intensity as well as by altering the type of muscle contraction to include isometric, concentric and eccentric muscle activity. Landing, cutting and plyometric exercises varied phase to phase but reflected sport-specific skills such as jumping to catch a high ball and progressed in difficulty. Variations included progressing from a single cutting manoeuvre to a cut, spin and accelerate movement pattern. Plyometric exercises progressed through each of the phases beginning with lower-load doublelegged tasks to high-load single-legged tasks. Throughout the intervention warm-up, there was a consistent theme of quality of movement control and body alignment for delivery agents to feedback to the players (see online supplementary file for an example of one intervention phase). The intervention finished with the same high-intensity shuttle running exercises as the control programme.

\section{Blinding of clubs}

Club members were blind to which programme they received. Clubs were informed that they were involved in a study evaluating the efficacy of different combinations of exercises for injury risk reduction and that clubs throughout the country were using different exercise combinations. This was deemed a pragmatic approach to limit contamination due to clubs who, due to being randomly assigned, could be situated in close geographical proximity to other participating clubs.

\section{Programme delivery}

Each club was visited by a 'programme trainer' from the research group to train each club's nominated 'delivery agent' (commonly the strength and conditioning coach) in how to deliver the programme to their players. Seventy-four per cent of clubs $(n=60)$ received training before the start of preseason and $26 \%(n=21)$ received training before the start of the competitive season. Two clubs received training less than 5 weeks before the start of the season.

\section{Data collection}

Data were collected during the 2015-2016 English rugby union season from July 2015 to May 2016. Clubs nominated a programme coordinator to report first team match exposure, exercise programme compliance and match injuries on a weekly basis using standardised forms. Data collection forms were available in paper and electronic formats.

\section{Injury definitions}

All first-team match injuries that resulted in absence from match play for $\geq 8$ days were defined as a 'time-loss' injury, including both acute and overuse injuries. Injuries were recorded using the Orchard Sports Injury Classification System (V.8 $)^{25}$ detailing injury type and location. The date a player was fit to play was recorded as the return to play date. Overall injury incidence refers to injuries with a $\geq 8$ days time-loss. Severe injuries were defined as injuries with $>28$ days time-loss. ${ }^{26}$ Injury burden was defined as the total number of days lost from training or match play. Targeted injuries were defined as injuries to the lower limb (buttock, hip, upper leg, knee, lower leg, ankle and foot), head and neck, or shoulder (glenohumoral joint), with diagnoses limited to muscle strains, ligamentous sprains, joint and neurological injury that resulted in $\geq 8$ days time-loss. Diagnoses including haematoma, laceration/contusion, fracture and undiagnosed pain at any body site were excluded from the targeted injury analysis.

\section{Outcomes}

Injury burden was the primary outcome between trial arms for all injuries. Secondary outcomes included overall injury incidence, targeted injury incidence and targeted injury burden.

\section{Statistical methods}

Data analysis, computed using SPSS (V.22 for Windows, IBM) was performed on an intention-to-treat (last observation carried forward) basis with the control clubs as the reference group.

Injury burden (number of days absence per 1000 player match-hours) and 90\% CIs were estimated vis-à-vis for primary and secondary outcome measures of this study. Injury incidence was estimated as the number of injuries per 1000 player match-hours. The General Estimating Equation was used to conduct Poisson regression analysis and explore the effects of the intervention on injury outcomes. Club (cluster) and playing level (semiprofessional; amateur; recreational) were included as random effects, and analysis was offset for club match exposure. Overdispersion was controlled for using a Pearson $\chi^{2}$ scaling parameter. ${ }^{27}$ Club programme compliance was defined by two measures: overall club compliance (proportion of all possible sessions where the programme was delivered) and the number of club programme sessions/week. Overall compliance, adjusted for varying lengths of clubs' participation in the study and the proportion of compliant sessions, was measured as the number of compliant sessions/total potential compliant sessions. Results are presented as RR with 90\% CI and interpreted using Clinical-Magnitude Based Inferences. ${ }^{28}$ Ten per cent was considered the minimum effect, and threshold values for unlikely/harmful (25) and most/very unlikely $(0.5)^{28}$ were used to derive the OR for making clinical inference.

\section{RESULTS}

\section{Overview}

Eighty-one clubs were randomised to the intervention $(n=41)$ or control $(n=40)$ arm, of which forty clubs (intervention $=19$, control=21) dropped out or otherwise returned incomplete data. Forty-one clubs (intervention $=22$, control=19) returned complete data detailing 255 injuries averaging 5.5 \pm 5.7 injuries per intervention club and $7.0 \pm 5.1$ injuries per control club. Total player match exposure was 19560 hours (intervention $=9900$, control $=9660$ player match-hours), averaging $477 \pm 121$ player match-hours per club. Across the 41 clubs, 222 different players sustained $\geq 1$ injury. All injuries were reported as acute injuries, and the majority were associated with contact mechanisms $($ contact $=199(78 \%)$, non - contact $=56(22 \%))$. Player demographic information is displayed in table 1.

Table 1 Player demographics (mean, SD and number) for participants in the intervention and control arms

\begin{tabular}{llll}
\hline Level & Age (years) & Mass $(\mathrm{kg})$ & Height $(\mathrm{cm})$ \\
\hline All players & $25.5(5.6)$ & $94.4(13.9)$ & $181.6(7.3)$ \\
& $(\mathrm{n}=673)$ & $(\mathrm{n}=1346)$ & $(\mathrm{n}=1355)$ \\
Intervention & $26.1(5.7)$ & $93.6(13.3)$ & $181.8(7.5)$ \\
& $(\mathrm{n}=273)$ & $(\mathrm{n}=675)$ & $(\mathrm{n}=682)$ \\
Control & $25.0(5.5)$ & $95.2(14.5)$ & $181.4(7.1)$ \\
& $(\mathrm{n}=400)$ & $(\mathrm{n}=671)$ & $(\mathrm{n}=673)$ \\
\hline
\end{tabular}


Table 2 Incidence rate ratios by injury stratification (all injury, targeted injury) based on Poisson regression analysis adjusted for cluster and playing level

\begin{tabular}{|c|c|c|c|c|c|c|c|}
\hline & Arm & Clubs (n) & $\begin{array}{l}\text { Player match- } \\
\text { hours }\end{array}$ & $\begin{array}{l}\text { Injuries/days } \\
\text { lost count }\end{array}$ & $\begin{array}{l}\text { Rate per } 1000 \text { player } \\
\text { match-hours }(90 \% \mathrm{Cl})\end{array}$ & RR $(90 \% \mathrm{CI})$ & $\begin{array}{l}\text { Magnitude-based inference } \\
\text { (beneficial/trivial/harmful) (\%) }\end{array}$ \\
\hline \multicolumn{8}{|l|}{ Overall Injury } \\
\hline \multirow[t]{2}{*}{ All incidence } & Control & 19 & 9660 & 133 & $13.8(11.9$ to 15.9$)$ & $0.9(0.6$ to 1.3$)$ & Unclear (51/31/18) \\
\hline & Intervention & 22 & 9900 & 122 & 12.3 (10.6 to 14.3$)$ & & \\
\hline \multirow[t]{2}{*}{ Severe incidence } & Control & 19 & 9660 & 73 & 7.6 (6.2 to 9.2$)$ & $0.8(0.6$ to 1.3$)$ & Unclear $(63 / 25 / 12)$ \\
\hline & Intervention & 22 & 9900 & 62 & 6.3 (5.1 to 7.7 ) & & \\
\hline \multirow[t]{2}{*}{ Injury burden } & Control & 19 & 9660 & 6918 & 716 (621 to 826$)$ & $0.8(0.5$ to 1.4$)$ & Unclear (62/22/16) \\
\hline & Intervention & 22 & 9900 & 5783 & 584 (503 to 678) & & \\
\hline \multicolumn{8}{|l|}{ Targeted injury } \\
\hline \multirow[t]{2}{*}{ Injury incidence } & Control & 19 & 9660 & 96 & 9.9 (8.4 to 11.8$)$ & $0.6(0.4$ to 1.0$)$ & Likely beneficial $(92 / 7 / 1)$ \\
\hline & Intervention & 22 & 9900 & 62 & 6.3 (5.1 to 7.7 ) & & \\
\hline \multirow[t]{2}{*}{ Severe incidence } & Control & 19 & 9660 & 56 & 5.8 (4.7 to 7.2$)$ & $0.6(0.3$ to 1.0$)$ & Likely beneficial $(92 / 6 / 2)$ \\
\hline & Intervention & 22 & 9900 & 33 & 3.3 (2.5 to 4.4$)$ & & \\
\hline \multirow[t]{2}{*}{ Injury burden } & Control & 19 & 9660 & 5288 & 547 (463 to 647) & $0.6(0.3$ to 1.3$)$ & Unclear (80/11/9) \\
\hline & Intervention & 22 & 9900 & 3472 & 351 (285 to 432 ) & & \\
\hline
\end{tabular}

\section{Overall injuries}

Overall injury burden was 649 (90\% CI 570 to 740) days/1000 player match-hours where the incidence ( $\geq 8$ days time-loss) for both trial arms combined was 13.0 (90\% CI 11.8 to 14.4) injuries/1000 player match-hours. There were 135 severe injuries (>28 days time-loss) with an incidence of 6.9 (90\% CI 6.0 to 7.9) injuries/1000 player match-hours. Intention-to-treat analysis indicated no clear difference in overall injury burden (RR, 0.8; 90\% CI $0.5-1.4)$, overall injury incidence (RR, $0.9 ; 90 \%$ CI $0.6-1.3$ ) or severe injury incidence (RR, 0.8 ; 90\% CI 0.6-1.3) for the intervention compared with control group (table 2 and figure 2 ).

\section{Targeted injuries}

One hundred and fifty-eight injuries (62\% of all injuries) across both trial arms met the 'targeted injury' definition with a burden of 448 (90\% CI 393 to 510) days/1000 player match-hours and an incidence of 8.1 (90\% CI 7.1 to 9.2) injuries/1000 player match-hours. There were 89 severe targeted injuries with an incidence of 4.6 (90\% CI 3.8 to 5.4) injuries/1000 player matchhours. Poisson regression analysis indicated no clear difference (RR, 0.6; 90\% CI 0.3-1.3) in targeted injury burden for the intervention (table 3 and figure 3 ) compared with the control group. A likely beneficial $40 \%$ (RR, 0.6; 90\% CI 0.4-1.0) reduction in both overall targeted injury incidence and severe targeted injury incidence (RR, 0.6; 90\% CI 0.3-1.0) was identified for the intervention compared with control group.

\section{Specific body locations}

There was a likely beneficial $70 \%$ reduction in both burden (RR, $0.3 ; 90 \%$ CI 0.2-0.7) and incidence (RR, 0.3; 90\% CI 0.2-0.6)

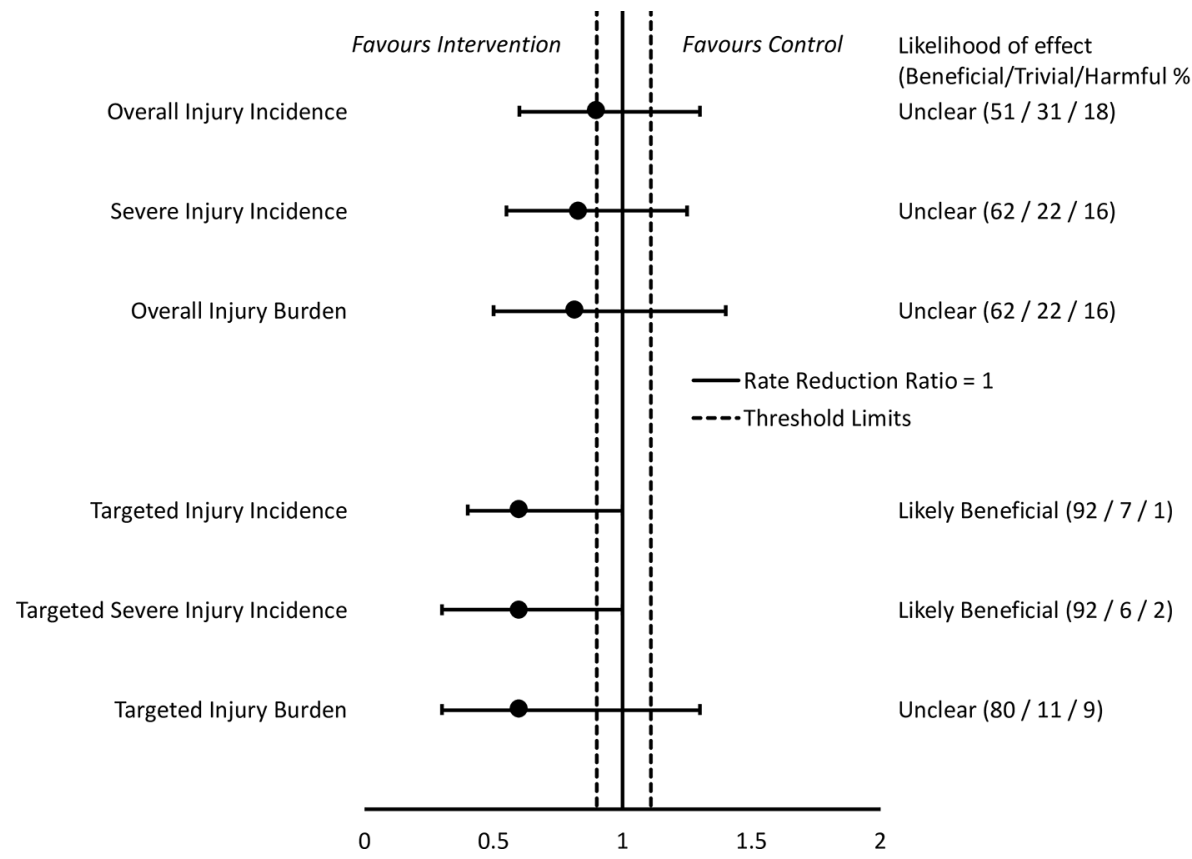

Figure 2 Rate reduction ratio (RR) and $90 \% \mathrm{Cl}$ of overall and targeted injury outcomes for the intervention group based on Poisson regression analysis adjusted for cluster and playing level. Clinical inference (right column) indicates the likelihood of effect. Vertical dashed lines represent $10 \%$ minimum effect thresholds, and the vertical solid line represents no effect compared with the control group. 
Table 3 Incidence rate ratios for targeted injuries, stratified by region (head and neck, shoulder and lower limb) based on Poisson regression analysis adjusted for cluster and playing level

\begin{tabular}{|c|c|c|c|c|c|c|}
\hline Target injury and arm & Clubs (n) & Player match-hours & $\begin{array}{l}\text { Injuries/days lost } \\
\text { count }\end{array}$ & $\operatorname{lIR}(90 \% \mathrm{CI})$ & $\operatorname{RR}(90 \% \mathrm{Cl})$ & $\begin{array}{l}\text { Magnitude-based inference } \\
\text { (beneficial/trivial/harmful) (\%) }\end{array}$ \\
\hline \multicolumn{7}{|l|}{ Head and neck incidence } \\
\hline Control & 19 & 9660 & 35 & $3.6(2.7$ to 4.8$)$ & \multirow[t]{2}{*}{$0.3(0.2$ to 0.7$)$} & \multirow[t]{2}{*}{ Very likely beneficial $(99 / 1 / 0)$} \\
\hline Intervention & 22 & 9900 & 12 & $1.2(0.8$ to 1.9$)$ & & \\
\hline \multicolumn{7}{|l|}{ Concussion incidence } \\
\hline Control & 19 & 9660 & 33 & $3.4(2.6$ to 4.5$)$ & \multirow[t]{2}{*}{$0.4(0.2$ to 0.7$)$} & \multirow[t]{2}{*}{ Very likely beneficial $(99 / 1 / 0)$} \\
\hline Intervention & 22 & 9900 & 12 & 1.2 (0.8 to 1.9$)$ & & \\
\hline \multicolumn{7}{|l|}{ Shoulder Incidence } \\
\hline Control & 19 & 9660 & 10 & $1.0(0.6$ to 1.7$)$ & \multirow[t]{2}{*}{$1.7(0.7$ to 3.8$)$} & \multirow[t]{2}{*}{ Likely harmful (11/10/79) } \\
\hline Intervention & 22 & 9900 & 17 & 1.7 (1.2 to 2.6$)$ & & \\
\hline \multicolumn{7}{|l|}{ Lower-limb incidence } \\
\hline Control & 19 & 9660 & 50 & $5.2(4.1$ to 6.5$)$ & \multirow[t]{2}{*}{$0.6(0.4$ to 1.0$)$} & \multirow[t]{2}{*}{ Likely beneficial (89/9/2) } \\
\hline Intervention & 22 & 9900 & 33 & $3.3(2.5$ to 4.4$)$ & & \\
\hline \multicolumn{7}{|l|}{ Head and neck burden } \\
\hline Control & 19 & 9660 & 1164 & $120(92$ to 159$)$ & \multirow[t]{2}{*}{$0.3(0.2$ to 0.7$)$} & \multirow[t]{2}{*}{ Very likely beneficial $(99 / 1 / 0)$} \\
\hline Intervention & 22 & 9900 & 378 & 38 (24 to 61$)$ & & \\
\hline \multicolumn{7}{|l|}{ Concussion burden } \\
\hline Control & 19 & 9660 & 983 & 102 (76 to 136$)$ & \multirow[t]{2}{*}{$0.4(0.2$ to 0.8$)$} & \multirow[t]{2}{*}{ Very likely beneficial (97/2/1) } \\
\hline Intervention & 22 & 9900 & 378 & 38 (24 to 61$)$ & & \\
\hline \multicolumn{7}{|l|}{ Shoulder burden } \\
\hline Control & 19 & 9660 & 436 & 45 (27 to 76$)$ & \multirow[t]{2}{*}{$1.5(0.6$ to 3.7$)$} & \multirow[t]{2}{*}{ Possibly harmful (17/11/71) } \\
\hline Intervention & 22 & 9900 & 673 & 68 (46 to 101$)$ & & \\
\hline \multicolumn{7}{|l|}{ Lower-limb burden } \\
\hline Control & 19 & 9660 & 3688 & 382 (303 to 482) & \multirow[t]{2}{*}{$0.6(0.3$ to 1.5$)$} & \multirow[t]{2}{*}{ Unclear (75/11/14) } \\
\hline Intervention & 22 & 9900 & 2421 & 245 (184 to 326) & & \\
\hline
\end{tabular}

$I I R$, injury incidence rate; $R R$, rate ratio.

of head and neck injury for the intervention group over control group (figure 3 and table 3). Forty-five of 47 'head and neck' injury diagnoses were concussion, and there was a likely beneficial $60 \%$ reduction in burden (RR, $0.4 ; 90 \%$ CI $0.2-0.8$ ) and incidence (RR, $0.4 ; 90 \%$ CI $0.2-0.7$ ) for this specific diagnosis in the intervention compared with the control group. Overall, twenty-seven injuries were reported for the shoulder (table 3) where a possibly harmful 50\% (RR, 1.5; 90\% CI 0.6-3.7) higher injury burden and likely harmful 70\% (RR, 1.7; 90\% CI 0.7-3.8) higher injury incidence was found for the intervention group

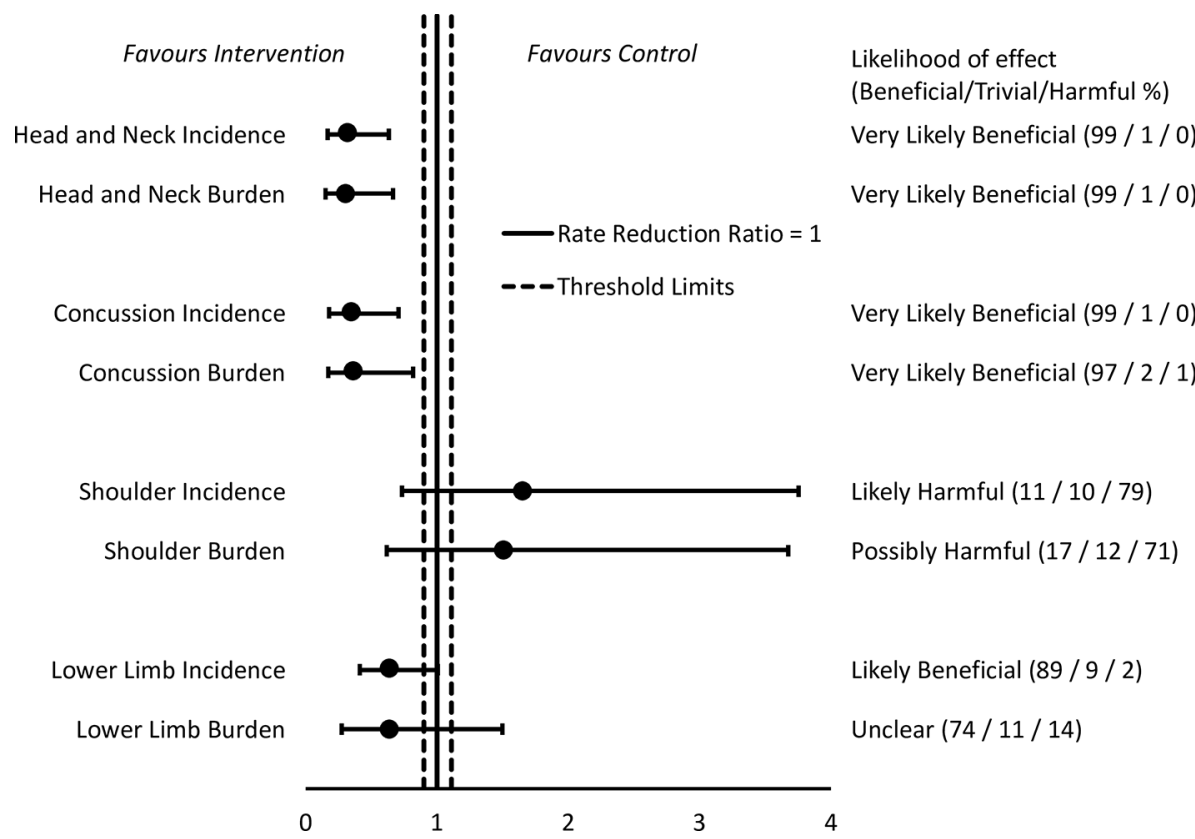

Figure 3 Rate reduction ratio (RR) and $90 \% \mathrm{Cl}$ for targeted injury outcomes stratified by location for the intervention group based on Poisson regression analysis adjusted for cluster and playing level. Clinical inference (right column) indicates the likelihood of effect. Vertical dashed lines represent $10 \%$ minimum effect thresholds, and the vertical solid line represents no effect compared with the control group. 
over control. There was no clear difference (RR, 0.6; 90\% CI $0.3-1.5$ ) in lower-limb injury burden but likely beneficial $40 \%$ (RR, $0.6 ; 90 \%$ CI $0.4-1.0)$ reduction in lower-limb injury incidence for the intervention compared with the control group.

\section{Programme compliance}

Programme compliance was high and was similar in both intervention $(2.1 \pm 0.7$ sessions $/$ week, median $=85 \%, I Q R=62-90)$ and control $(2.2 \pm 0.6$ sessions/week, median $=83 \%, \mathrm{IQR}=65-$ 92) study arms. Four clubs (intervention $n=3$, control $n=1$ ) completed their programme less than once weekly, 8 clubs (intervention $n=3$, control $n=5$ ) completed their programme at least once but less than twice weekly and 29 clubs (intervention $\mathrm{n}=16$, control $\mathrm{n}=13$ ) completed their programme at least twice weekly.

For clubs that completed the exercise programmes at least once weekly $(\mathrm{n}=37)$, no clear difference in targeted injury burden (RR, $0.7 ; 90 \%$ CI $0.3-2.0$ ) and likely beneficial $40 \%$ reduction (RR, 0.6 ; 90\% CI 0.4-1.0) in targeted injury incidence was found for the intervention compared with the control group.

Median compliance was used to divide clubs into higher $(\geq$ median $)$ and lower $(<$ median) compliance groups. Intervention clubs $(\mathrm{n}=11)$ with higher compliance displayed a very likely beneficial $60 \%$ reduction in both targeted injury burden (RR, $0.4 ; 90 \%$ CI $0.2-0.7)$ and targeted injury incidence (RR, $0.4 ; 90 \%$ CI $0.2-0.8$ ) compared with the control clubs with higher compliance $(n=9)$.

Within the intervention arm, comparison of clubs with higher compliance $(n=11)$ to lower compliance $(n=11)$ indicated a likely beneficial $50 \%$ reduction (RR, 0.5 ; 90\% CI 0.2-1.2) in targeted injury burden with no clear difference (RR, 0.7; 90\% CI 0.4-1.4) in targeted injury incidence for higher compliance clubs.

\section{DISCUSSION}

This is the first cluster randomised controlled trial to evaluate the efficacy of an injury prevention exercise programme to reduce injuries in adult men's community rugby players. No clear differences were found between intervention and control arms using intention-to-treat analysis and established clinical inference thresholds for overall injury burden, overall injury incidence or severe injury incidence. However, for injuries targeted by the intervention, overall injury incidence and severe injury incidence were both reduced by $40 \%$ in the intervention group compared with control, which were clear beneficial effects. Of particular note is that the intervention group benefited from a $60 \%$ reduction in concussion and a $40 \%$ reduction in lower-limb incidence compared with the control group.

\section{Targeted injuries}

Concussion was $60 \%$ lower for both incidence (1.2 vs 3.4 injuries/1000 player match-hours) and burden (38 vs 102 days/1000 player match-hours) in the intervention compared with the control group. This reduction is possibly a result of the isometric neck conditioning exercises included in every phase of the intervention programme. These exercises were included based on existing evidence that isometric neck exercises increase neck strength in male rugby players ${ }^{29}$ and that higher neck strength is suggested to decrease head accelerations during rugby collision events associated with concussion. ${ }^{30}$ For amateur rugby, this finding is very encouraging in the context of a proposed link between concussion sustained during a playing career and deficits in cognitive functioning in later life. ${ }^{31}$ Given the magnitude of the difference in concussion incidence between the intervention and control groups in this study, this is evidence to suggest that all adult men's community rugby players should engage in weekly neck conditioning exercises.

A likely beneficial reduction of $40 \%$ was found for targeted lower-limb injury incidence for the intervention group over control group (3.3 vs 5.2 injuries/1000 player match-hours). The intervention programme incorporated lower-limb balance, proprioception and movement control exercises similar in nature to exercises in FIFA $11+,{ }^{32}$ indicating that this approach is also efficacious for reducing injury in rugby, despite the high proportion of contact-related injuries. Intention-to-treat analysis from a neuromuscular-control intervention study in community adult men's Australian Rules Football, ${ }^{33}$ another sport with a high level of physical person-to-person contact, displayed a likely beneficial $20 \%$ reduction (RR, $0.8 ; 90 \%$ CI $0.6-1.0$ ) in lowerlimb injury incidence and a likely beneficial $50 \%$ reduction $(R R$, $0.5 ; 90 \%$ CI $0.3-1.0$ ) in knee injuries. Given that $\sim 50 \%$ of all community rugby injuries are lower-limb injuries, ${ }^{11}$ our findings support the completion of these lower-limb exercises as part of a warm-up before training and matches.

Shoulder injury incidence (1.7 vs 1.0 injuries/1000 player match-hours, respectively) and injury burden (68 vs 45 days/1000 player match-hours, respectively) was higher for the intervention group over control. Despite the higher rate of shoulder injuries, the intervention group had fewer shoulder dislocations (1 vs 5 dislocations) but more muscle/tendon injuries (15 vs 4 injuries) than the control group. There is no obvious explanation for the higher injury rate in the intervention group, though this trial was not powered to detect differences in shoulder injury rates as specific outcome. Reduced head and neck and lower-limb injuries likely resulted in greater individual player match exposure for players in the intervention arm. Greater player match exposure may have led to more shoulder contact events including tackles, thus increasing the risk for shoulder injury. All shoulder injuries were contact injuries and therefore may be harder to reduce via conditioning exercises alone. As reductions in both shoulder and head injury are likely achieved via good tackling technique, ${ }^{3435}$ it may be prudent that tackle education is recommended alongside implementation of this study's intervention.

\section{Compliance and injury risk}

Clubs' compliance rates were high, reflected by median compliance of $85 \%$ for the intervention group and $83 \%$ for the control group, where on average clubs implemented the programmes at least twice/week. Between-group comparison for clubs that completed the programme at least once/week during the season indicated a $40 \%$ reduction in targeted injury incidence for the intervention group over the control group. As some clubs only train once/week, it is encouraging to find that injury incidence was reduced provided clubs implemented the intervention once weekly. In soccer, higher FIFA $11+$ compliance produced a very likely beneficial $35 \%$ reduction in injury rates compared with intermediate FIFA $11+$ compliance. ${ }^{8}$ In the present study, comparison between intervention clubs with higher compliance to lower compliance ( $\geq 85 \%$ to $<85 \%$ of possible sessions) indicated a likely beneficial $50 \%$ reduction in targeted injury burden. This indicates that additional benefit can be achieved when the intervention is implemented in the majority of training sessions and before matches.

The control exercises reflected normal 'good practice' for this level of rugby and consisted of dynamic stretching and non-targeted 
resistance exercises. Overall injury incidence in the control group was 13.8 (90\% CI 11.9 to 15.9 ) injuries/1000 player match-hours, which is $18 \%$ lower than the incidence previously reported for similar populations of adult men's community rugby players (16.9 injuries/1000 player match-hours; 90\% CI 14.9-16.5). ${ }^{11}$ Control exercises may have offered better physical preparation for players than current 'normal practice', which is supported by feedback from pilot study delivery agents (unpublished data; Attwood, 2017). Results may indicate that there is a need to improve warm-up practices in this population.

Implementation in the 'real-world' setting is needed before intervention effectiveness can be determined. ${ }^{36}$ The full potential of this intervention programme will only be realised if it is adopted, executed correctly and maintained ${ }^{3637}$ by community rugby clubs. The RFU has identified player welfare as a strategic priority and is ideally placed to disseminate the intervention to community rugby clubs in England with its employed, field-based workforce. However, this will not be without its challenges and following nationwide dissemination, intervention programme effectiveness will need to be evaluated using the RE-AIM framework. ${ }^{38}$

\section{Strengths and limitations}

Random checks of club compliance through unannounced visits were not made, which would have increased the validity of the compliance results. Regarding compliance, it was assumed participants must ' $\mathrm{do}$ as they are told ${ }^{39}$ and thus completed their programme in full as was designed. The efficacy of the intervention reflects reductions in musculoskeletal injury and concussion found in schoolboy rugby ${ }^{40}$ using a similar intervention. ${ }^{41} \mathrm{~A}$ cluster randomised controlled trial reduces biases associated with the results and the pragmatic, coach (delivery agent)-led delivery approach increased the generalisability of the study results. This coach-led, club-based warm-up intervention programme, which included balance and proprioception exercises, resistance and

\section{What are the findings?}

- This study is the first to demonstrate the efficacy of an injury prevention exercise programme in adult men's community rugby.

- Performing at least one movement control session per week led to reduced injury rates.

- Lower-limb injury, head and neck injury and concussion were reduced, but shoulder injuries were increased in the intervention group undertaking exercises during warm-ups at training and before matches.

- Higher compliance with the intervention programme was associated with the greatest injury reduction.

\section{How might it impact on clinical practice in the near}

\section{future?}

- The injury prevention exercise programme should be performed prior to training and matches in all adult men's rugby union.

- Given the evidence for the efficacy of this and similar injury prevention exercise programmes, practitioners should consider the content of the 'warm-up' and consider employing the principles of these exercise programmes regardless of which sport they are working in. perturbation exercises and sport-related landing, cutting and plyometric exercises, is efficacious in reducing overall targeted injury and severe injury in adult men's community rugby and should be implemented nationwide.

\section{CONCLUSION}

This is the first cluster randomised controlled trial to examine the efficacy of a movement control injury prevention programme in adult men's community rugby players. The intervention programme demonstrated clear beneficial effects by reducing concussion incidence by $60 \%$ and lower-limb injury incidence by $40 \%$ compared with control. It is recommended that adult men's rugby players complete the intervention programme exercises prior to training and match play.

Acknowledgements The authors would like to acknowledge the input of the project's technical groups' participants: Matthew Cross, Alasdair Dempsey, Carolyn Emery, Michael Hislop, Tim Lawrenson, Richard Mack, Carly McKay, Katie Morris, Simon Roberts, Des Ryan, Vincent Singh, Paul Tompkins, Evert Verhagen, Shaun Williams.

Contributors KAS, GT, SPR and MEE initiated the overall project. MJA, KAS, GT, SPR and MEE conceived and designed the study. MJA, KAS, GT and SPR collected and analysed data. MJA prepared the first draft of the manuscript. All authors made substantial contributions to revision of the document prior to submission.

Funding This research is funded by the Rugby Football Union and the Private Physiotherapy Education Fund.

Ethics approval Research Ethics Approval Committee for Health at the University of Bath.

Provenance and peer review Not commissioned; externally peer reviewed. Data sharing statement No additional data are currently available.

Open Access This is an Open Access article distributed in accordance with the Creative Commons Attribution Non Commercial (CC BY-NC 4.0) license, which permits others to distribute, remix, adapt, build upon this work non-commercially, and license their derivative works on different terms, provided the original work is properly cited and the use is non-commercial. See: http://creativecommons.org/ licenses/by-nc/4.0/

(c) Article author(s) (or their employer(s) unless otherwise stated in the text of the article) 2018. All rights reserved. No commercial use is permitted unless otherwise expressly granted.

\section{REFERENCES}

1 Hägglund M, Atroshi I, Wagner P, et al. Superior compliance with a neuromuscular training programme is associated with fewer $\mathrm{ACL}$ injuries and fewer acute knee injuries in female adolescent football players: secondary analysis of an RCT. Br J Sports Med 2013:46:974-9.

2 Williams S, Trewartha G, Kemp SP, et al. Time loss injuries compromise team success in Elite Rugby Union: a 7-year prospective study. Br J Sports Med 2015;50:651-6.

3 RFU. Recruitment and retention - Play 2011, 2011. http://www.rfu.com/ managingrugby/cbmanagement/ /media/files/2010/managingrugby/cbmanagement/ cb_1602/9380_play2011_andy_lees_v3.ashx (accessed 11 Dec 2013).

4 Grimmer KA, Jones D, Williams J. Prevalence of adolescent injury from recreationa exercise: an Australian perspective. J Adolesc Health 2000;27:266-72.

5 Maffulli N, Longo UG, Gougoulias N, et al. Long-term health outcomes of youth sports injuries. Br J Sports Med 2010:44:21-5.

6 Lohmander LS, Ostenberg A, Englund M, et al. High prevalence of knee osteoarthritis, pain, and functional limitations in female soccer players twelve years after anterior cruciate ligament injury. Arthritis Rheum 2004;50:3145-52.

7 Salaffi F, Carotti M, Stancati A, et al. Health-related quality of life in older adults with symptomatic hip and knee osteoarthritis: a comparison with matched healthy controls. Aging Clin Exp Res 2005;17:255-63.

8 Soligard T, Myklebust G, Steffen K, et al. Comprehensive warm-up programme to prevent injuries in young female footballers: cluster randomised controlled trial. BMJ 2008:337:a2469.

9 Steffen K, Emery CA, Romiti M, et al. High adherence to a neuromuscular injury prevention programme (FIFA 11+) improves functional balance and reduces injury risk in Canadian youth female football players: a cluster randomised trial. $\mathrm{Br}$ J Sports Med 2013;47:794-802.

10 Grooms DR, Palmer T, Onate JA, et al. Soccer-specific warm-up and lower extremity injury rates in collegiate male soccer players. J Ath/ Train 2013:48:782-9. 
11 Roberts SP, Trewartha G, England M, et al. Epidemiology of time-loss injuries in English community-level rugby union. BMJ Open 2013;3.

12 McNoe BM, Chalmers DJ. Injury in Community-Level Soccer. Am J Sports Med 2010;38:2542-51.

13 Hendricks S, Matthews B, Roode B, et al. Tackler characteristics associated with tackle performance in rugby union. Eur J Sport Sci 2014;14:753-62.

14 Roberts SP, Trewartha G, England M, et al. Concussions and Head Injuries in English Community Rugby Union Match Play. Am J Sports Med 2017:45:480-7.

15 Headey J, Brooks JH, Kemp SP. The epidemiology of shoulder injuries in English professional rugby union. Am J Sports Med 2007;35:1537-43.

16 Crichton J, Jones DR, Funk L. Mechanisms of traumatic shoulder injury in elite rugby players. Br J Sports Med 2012;46:538-42.

17 LaBella CR, Huxford MR, Grissom J, et al. Effect of neuromuscular warm-up on injuries in female soccer and basketball athletes in urban public high schools: cluster randomized controlled trial. Arch Pediatr Adolesc Med 2011;165:1033-40.

18 Petersen J, Thorborg K, Nielsen MB, et al. Preventive Effect of Eccentric Training on Acute Hamstring Injuries in Men's Soccer. Am J Sports Med 2011;39:2296-303.

19 Longo UG, Loppini M, Berton A, et al. The FIFA 11+ program is effective in preventing injuries in elite male basketball players: a cluster randomized controlled trial. Am J Sports Med 2012;40:996-1005.

20 Falese L, Della Valle P, Federico B. Epidemiology of football (soccer) injuries in the 2012/2013 and 2013/2014 seasons of the Italian Serie A. Res Sports Med 2016;24:426-32.

21 Campbell MK, Piaggio G, Elbourne DR, et al. Consort 2010 statement: extension to cluster randomised trials. BMJ 2012;345:e5661.

22 Hayes RJ, Bennett S. Simple sample size calculation for cluster-randomized trials. Int J Epidemiol 1999;28:319-26.

23 Roberts SP, Trewartha G, England M, et al. Epidemiology of time-loss injuries in English community-level rugby union. BMJ Open 2013;3:e003998.

24 Jeffreys I. Warm up revisited-the 'ramp'method of optimising performance preparation. UKSCA Journal 2006;6:15-19.

25 Rae K, Britt H, Orchard J, et al. Classifying sports medicine diagnoses: a comparison of the International classification of diseases 10-Australian modification (ICD-10AM) and the Orchard sports injury classification system (OSICS-8). Br J Sports Med 2005:39:907-11.

26 Fuller CW, Molloy MG, Bagate C, et al. Consensus statement on injury definitions and data collection procedures for studies of injuries in rugby union. Clin J Sport Med 2007;17:177-81.

27 McCullagh P, Nedler JA. Generalized linear models: CRC Press, 1989.
28 Hopkins WG, Batterham AM. Error rates, decisive outcomes and publication bias with several inferential methods. Sports Med 2016;46:1563-73.

29 Geary K, Green BS, Delahunt E. Effects of neck strength training on isometric neck strength in rugby union players. Clin J Sport Med 2014;24:502-8.

30 Dempsey A R, Fairchild T J, Appleby BB. The relationship between neck strength and head accelerations in a rugby tackle. 33rd International Conference on Biomechanics in Sports. Poitiers, France, 2015.

31 Hume PA, Theadom A, Lewis GN, et al. A comparison of cognitive function in former rugby union players compared with former non-contact-sport players and the impact of concussion history. Sports Med 2017;47:1209-20.

32 Bizzini M, Dvorak J. FIFA 11+: an effective programme to prevent football injuries in various player groups worldwide-a narrative review. Br J Sports Med 2015;49:577-9.

33 Finch CF, Twomey DM, Fortington LV, et al. Preventing Australian football injuries with a targeted neuromuscular control exercise programme: comparative injury rates from a training intervention delivered in a clustered randomised controlled trial. Inj Prev 2016;22:123-8

34 Burger $\mathrm{N}$, Lambert MI, Viljoen W, et al. Mechanisms and factors associated with tackle-related injuries in South African youth rugby union players. Am J Sports Med 2017;45:278-85

35 Tucker R. Decision-making and technique: Evidence for increased head injury risk during tackling in rugby union. Br J Sports Med 2017;51:398.3-9.

36 Finch C. A new framework for research leading to sports injury prevention. J Sci Med Sport 2006;9:3-9.

37 O'Brien J, Finch CF. The implementation of musculoskeletal injury-prevention exercise programmes in team ball sports: a systematic review employing the RE-AIM framework. Sports Med 2014;44:1425-30.

38 Glasgow RE, Vogt TM, Boles SM. Evaluating the public health impact of health promotion interventions: the RE-AIM framework. Am J Public Health 1999;89:1322-7.

39 McKay CD, Verhagen E. 'Compliance' versus 'adherence' in sport injury prevention: why definition matters. Br J Sports Med 2016;50:382-3.

40 Hislop MD, Stokes KA, Williams S, et al. Reducing musculoskeletal injury and concussion risk in schoolboy rugby players with a pre-activity movement control exercise programme: a cluster randomised controlled trial. Br J Sports Med 2017;51:1140-6.

41 Hislop MD, Stokes KA, Williams $\mathrm{S}$, et al. The efficacy of a movement control exercise programme to reduce injuries in youth rugby: a cluster randomised controlled trial. BMJ Open 2016:2:e000043. 